\title{
MATHEMATICAL MODELING OF THE SYSTEM SHEDDING MOTION - HEALD - WARP
}

\author{
Martin Bílek, Josef Skřivánek \\ Department of Textile Machine Design of Technical University of Liberec, Studentská 2, Czech Republic \\ E-mail: martin.bilek@tul.cz, josef.skrivanek@tul.cz
}

\begin{abstract}
:
The paper is concerned with the description of a mathematical model meant for an analysis of the movement of healds during the weaving cycle. The referred model consists of a mathematical description of shedding motion, coupled with the solution of the heald model of a weaving loom. Principal designing elements of this component have been considered while devising this model. The affected calculations show a high value of acceleration of the heald produced after its drop upon the supporting wire. The referred model allows for analyzing a considerable part of designs of heald shaft that are employed in weaving looms nowadays.
\end{abstract}

\section{Keywords:}

Weaving loom, heald, mathematical model, analysis

\section{Introduction}

In general, the shedding mechanism can be classified into two sections: the driving section and the transforming section. The transforming section of the shedding mechanism consists of joint mechanisms usually, which convert the rotational motion of the driving section into a feed reverse motion of the heald shaft. The course of load exerted upon the heald shaft depends upon the design of the parts of mechanism

The heald shaft is the frame in which there are fastened the healds governing warp threads. The healds are fastened in this frame with a necessary designing play. Because of textile technology reasons, this play must allow axial displacement of the loom along the support wire. As the heald shaft performs feed reverse movement, the system of healds gets transferred during the weaving cycle. This transfer produces a load on the supporting wire upon which the healds drop down, bringing as a consequence an increased stress of the whole shedding mechanism. During the weaving process the heald is always coupled with one of the pair of main beams of the heald shaft only.

\section{Mathematical model of the shedding motion}

In view of the fact that the lifting section of the shedding motion is a joint mechanism, a number of procedures and methods can be employed for the modeling of the above structure. It is possible to apply successfully the description of a mechanism based upon the method of devising motion equations by means of Lagrangian equations of the $2^{\text {nd }}$ type according to $[1,2]$.

In the model, the motion of healds considering clearances between healds and the heald rod, in heald eye between the heald and warp thread during one turn of looms' main shaft, is analyzed. The results are represented by graphs of kinematic quantities on individual elements of mechanism that depend on mass parameters (rigidity, moment of inertia, mass) and on clearances in kinematic pairs of the mechanism (Figure 1).

This system is a complicated one as for the number of elements and the kinematic pairs. Mathematical model of the shedding mechanism has been formulated with the following assumptions:

a) mass of heald shaft and elements 7, 8, 9 are reduced to the joints of the elements 4 and 6 ,

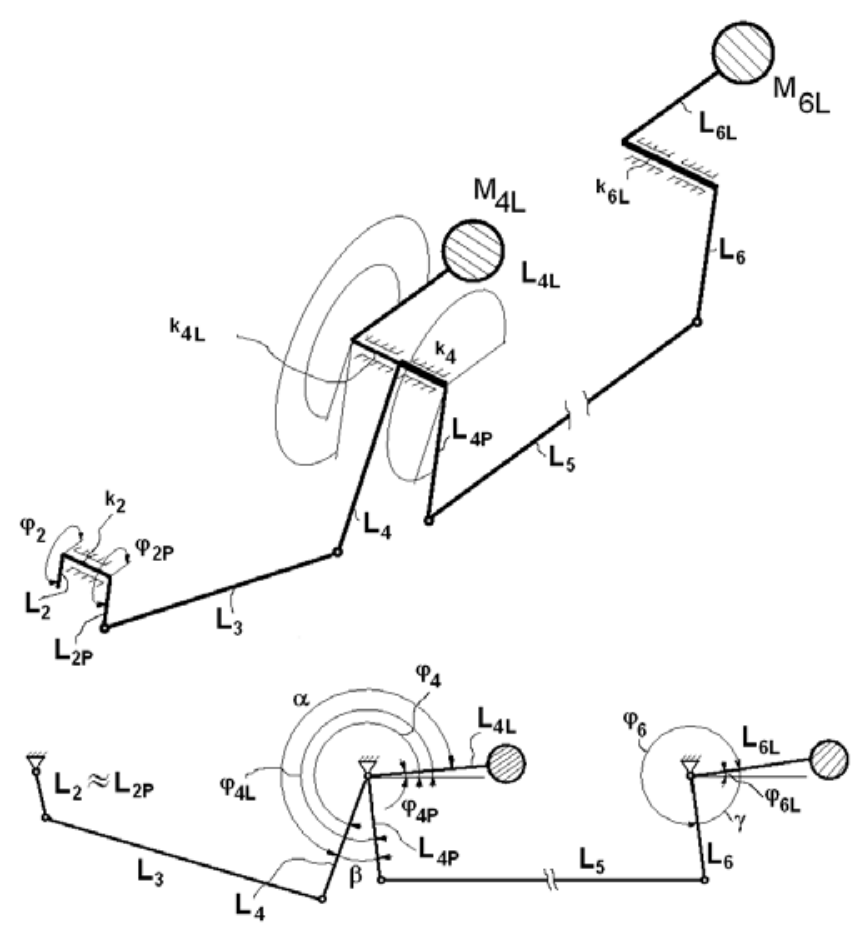

Figure 1. Scheme of mathematical model of the shedding motion. 
b) mass of elements 3,5 are replaced by two masses concentrated in points and are considered as rigid,

c) rocking levers of elements 2, 4, 6 are rigid and are mutually joined by torsical rods,

d) clearances in kinematic pairs are considered in elements 2 and 4 , and

e) viscous damping in individual elements is also considered in the model.

Equations of motion of the system are formulated using Lagrange's equation of the type II in the form

$$
\frac{d}{d t}\left(\frac{d K}{d \dot{q}_{i}}\right)-\frac{\partial K}{\partial q_{i}}=-\frac{\partial U}{\partial q_{i}}-\frac{\partial R}{\partial \dot{q}_{i}}
$$

where $\mathrm{i}=2,4,6$. (K - kinetic energy, $\mathrm{U}$ - potential energy, $\mathrm{R}$ dissipative function.)

Substituting different parameters $\mathrm{K}, \mathrm{U}$, and $\mathrm{R}$ in equation (1), we obtain the following equations of motion:

$$
\begin{aligned}
& \varphi_{2 P}\left(I_{2 P}+I_{4} \mu_{24}^{2}\right)=-I_{4} \cdot \mu_{24} \cdot v_{24} \cdot \varphi_{2 P}^{2}-k_{2}\left(\varphi_{2 P}-\varphi_{2}\right)+k_{4} \mu_{24}\left(\varphi_{4 P}-\varphi_{4}+\beta\right)+ \\
& +b_{2}\left(\varphi_{2 P}-\varphi_{2}\right)+b_{4} \mu_{24}\left(\varphi_{4 P}-\varphi_{4}\right) \\
& \ddot{\varphi}_{4 P}\left(I_{4}+I_{6} \mu_{46}^{2}\right)=-I_{6} \cdot \mu_{46} \cdot v_{46} \cdot \dot{\varphi}_{4 P}^{2}-k_{4}\left(\varphi_{4 P}-\varphi_{4}+\beta\right)+k_{6 L} \mu_{46}\left(\varphi_{6 L}-\varphi_{6}-\gamma\right)+ \\
& +b_{4}\left(\dot{\varphi}_{4 P}-\dot{\varphi}_{4}\right)+b_{6 L} \mu_{46}\left(\dot{\varphi}_{6 L}-\dot{\varphi}_{6}\right) \\
& \varphi_{4 L} I_{4 L}=-k_{4 L}\left(\varphi_{4 L}-\varphi_{4}-\alpha\right)-b_{4 L}\left(\varphi_{4 L}-\varphi_{4}\right)-M_{4 L}+F_{N L} L_{4 L} \cos \varphi_{4 L} \\
& \varphi_{6 L} I_{6 L}=-k_{6 L}\left(\varphi_{6 L}-\varphi_{6}-\gamma\right)-b_{6 L}\left(\varphi_{6 L}-\varphi_{6}\right)-M_{6 L}+F_{N L} L_{6 L} \cos \varphi_{6 L}
\end{aligned}
$$

Clearances occurring in the kinematic pairs of the chains are replaced by angular differences of elements 2 and 4, which are incorporated into the model under the following conditions:

$$
\begin{aligned}
& \left|\varphi_{i P}-\varphi_{i}\right| \leq \Phi_{i} \Rightarrow \varphi_{i P}-\varphi_{i}=0 \\
& \varphi_{i P}-\varphi_{i}>\Phi_{i} \Rightarrow \varphi_{i P}-\varphi_{i}=\varphi_{i P}-\varphi_{i}-\Phi_{i} \\
& \varphi_{i P}-\varphi_{i}<-\Phi_{i} \Rightarrow \varphi_{i P}-\varphi_{i}=\varphi_{i P}-\varphi_{i}+\Phi_{i}
\end{aligned}
$$

here $\mathrm{i}=2,4$.

An experimental verification of the employed model of mechanical structure of the joint mechanism is described in [3]. The referred universal mathematical model of the shedding motion can be modified in a simple manner by entering the timedependent lift dependence on the driving element, defining the course of its angular displacement. For example, it is possible to realize in this manner a calculation of the movement of a rotational dobby which is described in [4-8].

\section{Mathematical model of the heald}

\subsection{Description of the heald problem}

The studies realized up to now have shown that the heald is one of the most important parts of the shedding motion and it exerts an important effect upon its dynamic loading. Some analyses have been dealt with in this process experimentally $[9,10]$. Because of this reason, it also constitutes one of the limiting elements impeding to increase its operational revolutions. In order to be able to describe the behavior of the heald during the weaving process, it is necessary to devise a suitable mathematical model that will describe its behavior during the operating cycle with a defined precision. The heald is influenced by a number of forces, which determine with which supporting wire it will be coupled. The most important ones are the dynamic force of the heald, the warp forces in the sense of movement of the shaft and the weight of the heald $[11,12]$.

An important designing element influencing the behavior of the heald is the play in its fastening in the frame of the heald shaft. In the mathematical model, this play can be defined by means of the difference of positions of the upper and lower support wires. The distance of the lower support wire is shifted with respect to the position of the upper one by the extent of the fastening play. Thanks to this play, the forces in the warp threads are transmitted upon one of the couplings of the rods of the heald shaft only. For analysis of movement of the heald, we will assume that the frame of the shaft is absolutely rigid. In the mathematical model, this presumption will be reflected by the unchanging distance of both supporting wires in the course of the whole calculation, corresponding to the solution of movement of a heald fastened in the vicinity of the edge of a heald shaft. At present, the deformation of the main beams of the heald shaft during the working process are minimized by employing new types of composite rods.

As mentioned in the introduction, nowadays flat healds are employed that are made of a flat steel band by the pressing process. On the body of the heald, there are a number of orifices and stampings that serve e.g. for drawing-in machines or for other technological purposes. These shape parameters influence the strength and rigidity of the heald. Some healds have a stamping in the position of one suspension eye, which ought to provide for mutual spacing of healds; however, it reduces the rigidity of the suspension eye at the same time. Because of this reason, mathematical models are needed keeping in mind different rigidities of the upper and lower sections of the heald. In the mathematical model of the heald, we employ the Newtonian impact theory. The description of the fall of the heald upon the supporting wire employs the presumption of a perfectly elastic impact. We presume the velocity of the fall of the heald upon supporting wire up to $1 \mathrm{~m} \cdot \mathrm{s}^{-1}$.

The following part of the text describes the assembly of the model of a heald, by means of which we are able to find with which supporting wire the heald is coupled in a given moment. The motion equations describing the movement of the heald during the weaving process are complemented with motion equations of the shedding motion. In all compiled models, the mass of the heald $m n$ is concentrated in one mass point. The force To from the warp operates in the position of the thread eyelet. The mechanical properties of the yarn which is determined by the force of the warp in the mathematical model were determined experimentally [13-15]. The point 
of application of this force is located in one mass point. It is possible to disregard the bowing of the heald due to its lateral loading. The devised models proceed from the assumption that the movement of the mass point substituting the heald is carried out on a straight line. In the solution of the system, the positions of the upper supporting wire $(y h)$ and of the lower one $(y d)$, position of the heald $(y n)$, and position of the warp thread (yo) were established. The extent of the play in the fastening of the heald on the support wire is determined by the parameter $f$. The compiled models of the heald also consider the effect of the dimension of the thread eyelet $\mathrm{J}$ upon the course of the force in the warp.

The initial conditions of the solution proceed from the presumption that the heald is entrapped on the upper supporting wire, and both its velocity and acceleration are identical with those of the upper supporting wire.

The solution of individual mathematical models has been realized by means of a devised software program. The solution of compiled differential equations describing the shedding motion coupled with an analysis of the movement of heald during the weaving cycle has been affected by the Runge-Kutt method of the $4^{\text {th }}$ order. During the calculation, the courses of the principal kinematic and force quantities of the system have been studied.

\subsection{Solution of the heald problem}

The system subject to solution can be represented schematically according to Figure 2. The body of the heald is modeled by means of the Kelvin-Voigt visco-elastic rheologic model with the rigidity $\mathrm{k}_{\mathrm{nH}}$ and co-efficient of viscous damping $\mathrm{b}_{\mathrm{nH}}$ in the upper part, and the rigidity $k_{n D}$ and co-efficient of viscous damping $b_{n D}$ in the lower part of the heald. A general motion equation of this model can be written as

$$
\begin{aligned}
& m_{n} \cdot \ddot{y}_{n}=T_{o}-m_{n} \cdot g+H \cdot k_{n H} \cdot\left(y_{h}-y_{n}\right)+H \cdot b_{n H} \cdot\left(\dot{y}_{h}-\dot{y}_{n}\right)- \\
& -D \cdot k_{n D} \cdot\left(y_{n}-y_{d}\right)-D . b_{n D} \cdot\left(\dot{y}_{n}-\dot{y}_{d}\right)
\end{aligned}
$$

The conditions for the solution of the concerned equation follow from an equilibrium of forces on the heald, and - as mentioned above - they consider the play in the fastening of the heald on the supporting wire. The control constants $\mathrm{H}$ and $\mathrm{D}$ assume the values 0 and 1 , and they determine which members of the equation will be employed in the calculation.
The individual phases of the solution of the concerned model can be resolved by means of equations (10) - (13). The start of the solution proceeds from the motion equation (10).

$$
\ddot{y}_{n}=\frac{T_{o}}{m_{n}}-g+\frac{k_{n H}}{m_{n}} \cdot\left(y_{h}-y_{n}\right)+\frac{b_{n H}}{m_{n}} \cdot\left(\dot{y}_{h}-\dot{y}_{n}\right)
$$

In the moment of equality (11), the heald leaves the upper supporting wire, and there follows a transfer of the heald between the main beams, which is solved according to equation (12).

$$
\begin{aligned}
& m_{n} \cdot y_{n}-T_{o}+m_{n} \cdot g=0 \\
& y_{n}=\frac{T_{o}}{m_{n}}-g
\end{aligned}
$$

The transfer is completed when the conditions (14) or (15) are fulfilled. The first potential state is the return of the heald on the upper rod (the condition 15 is fulfilled). In such a case, the movement of the heald is solved again according to equation (10).

If condition (14) has been fulfilled, the heald is entrapped on the lower supporting wire and the acceleration of the heald is solved according to relation (13).

$$
\begin{aligned}
& \ddot{y}_{n}=\frac{T_{o}}{m_{n}}-g-\frac{k_{n}}{m_{n}} \cdot\left(y_{n}-y_{d}\right)-\frac{b_{n}}{m_{n}} \cdot\left(\dot{y}_{n}-\dot{y}_{d}\right) \\
& y_{n}=y_{h}+\phi \\
& y_{n}=y_{h}
\end{aligned}
$$

The separation of the heald from the lower supporting wire will start in the moment when equality (11) is fulfilled. This transfer is again solved by means of motion equation (12). Once again, it is necessary to check two limit states. The first one is the return of the heald onto the lower rod (condition 14 has been satisfied), the second limit state is entrapping of the heald on the upper support wire (condition 15 has been fulfilled). If condition (14) is fulfilled, the solution of the motion of the heald will be realized employing motion equation (13). If condition (15) has been fulfilled, the movement of the heald is solved by the equation motion in form (10).

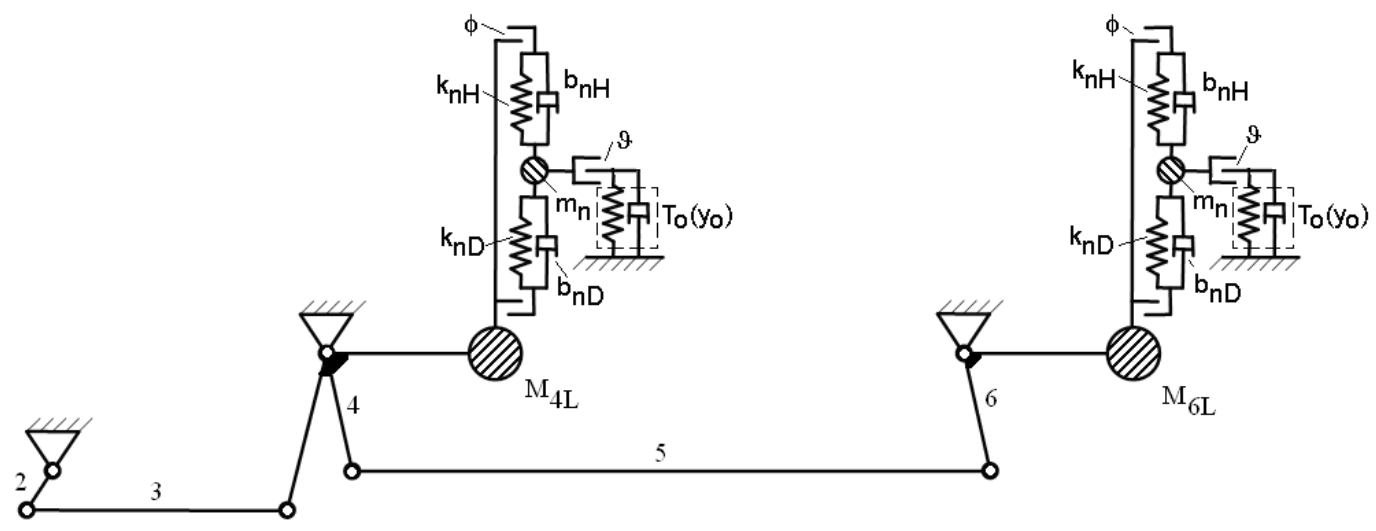

Figure 2. Schematic model of the system shedding mechanism - heald. 
The effect of the thread eyelet is included in the calculation by means of the following conditions:

$$
\begin{aligned}
& \left|y_{n}\right| \leq \frac{\vartheta}{2} \Rightarrow y_{O}=0 \\
& y_{n}>\frac{\vartheta}{2} \Rightarrow y_{O}=y_{n}-\frac{\vartheta}{2} \\
& y_{n}<-\frac{\vartheta}{2} \Rightarrow y_{O}=y_{n}+\frac{\vartheta}{2}
\end{aligned}
$$

\section{$\underline{3.3 \text { Results }}$}

The control algorithm of the calculation checks the position of the heald with respect to the supporting wire of the heald shaft. As mentioned above, four possible states can arise which have been studied and on the basis of the realized calculation of the movement of the heald. An example of calculated dependencies is given in Figure 3, showing the principal kinematic courses of the supporting wire and of the heald. The calculation has been realized for the velocity of the shedding motion 300 r.p.m. An example of the course of calculation in case of this model is given in Figure 4.

\section{Conclusion}

For the generation of a real mathematical model, the model with the rigidity substitution of the heald by means of the KelvinVoigt visco-elastic model has proved suitable. The referred enhancement allows for determining the number and extent of bounces of the heald from the supporting wire after its transfer between individual supporting wires. In this mathematical model, it is possible to ascertain the moment of separation of the heald from the supporting wire as well as the time of transfer of the heald between main beams of the heald shaft. By means of this model, it is possible to determine the loads exerted upon individual end eyelets of the heald. The affected calculations show a high value of acceleration of the heald produced after its drop upon the supporting wire. The referred model allows for analyzing a considerable part of designs of the heald shaft that are employed in weaving looms nowadays.

From the detailed analysis of theoretical calculation obtained for different operating frequencies, it has been found that the moments of the drop or of the separation of the heald from the supporting wire are comparable with records of the acceleration. From the record, the behavior of the heald upon the supporting wire depending upon the operating frequency can be seen. An important factor, which can be evaluated, is the number of bounces of the heald after the drop upon the supporting wire, after the transfer between the main beams of the heald shaft.

This coincidence of experimental results and calculated values obtained from the mathematical model constitutes a basic condition for a more extensive analysis of the system, with the aim to describe the behavior of the heald during weaving cycle and to propose possible adaptations of the design.

Dedication: The paper has been elaborated with financial support of TUL in the framework of specific university research competition.

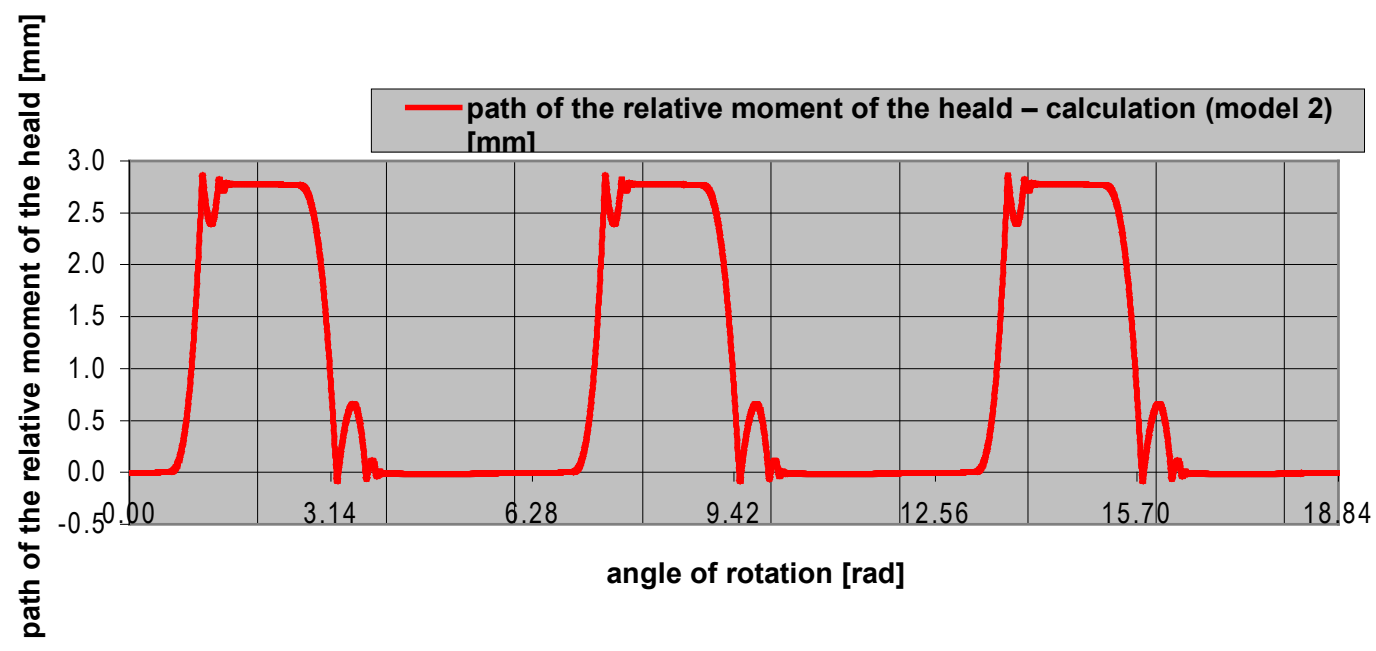

Figure 3. Relative movement of the heald with respect to upper supporting wire, operating velocity of the shedding motion 300 r. p.m.

Table 1. Maximal value of acceleration after its transfer between individual supporting wires.

\begin{tabular}{|l|c|c|c|}
\hline \multirow{2}{*}{ Maximal value of acceleration of heald after its transfer on upper rod $\left[\mathrm{m} . \mathrm{s}^{-2}\right]$} & 1220 & $\mathbf{3}$ Shedding motion rpm \\
\cline { 2 - 4 } & $\mathbf{1 5 0} \mathbf{~ r p m}$ & $\mathbf{3 0 0} \mathbf{~ r p m}$ & $\mathbf{4 5 0} \mathbf{~ r p m}$ \\
\hline Maximal value of acceleration of heald after its transfer on lower rods $\left[\mathrm{m} . \mathrm{s}^{-2}\right]$ & 671 & 906 & 1477 \\
\hline
\end{tabular}



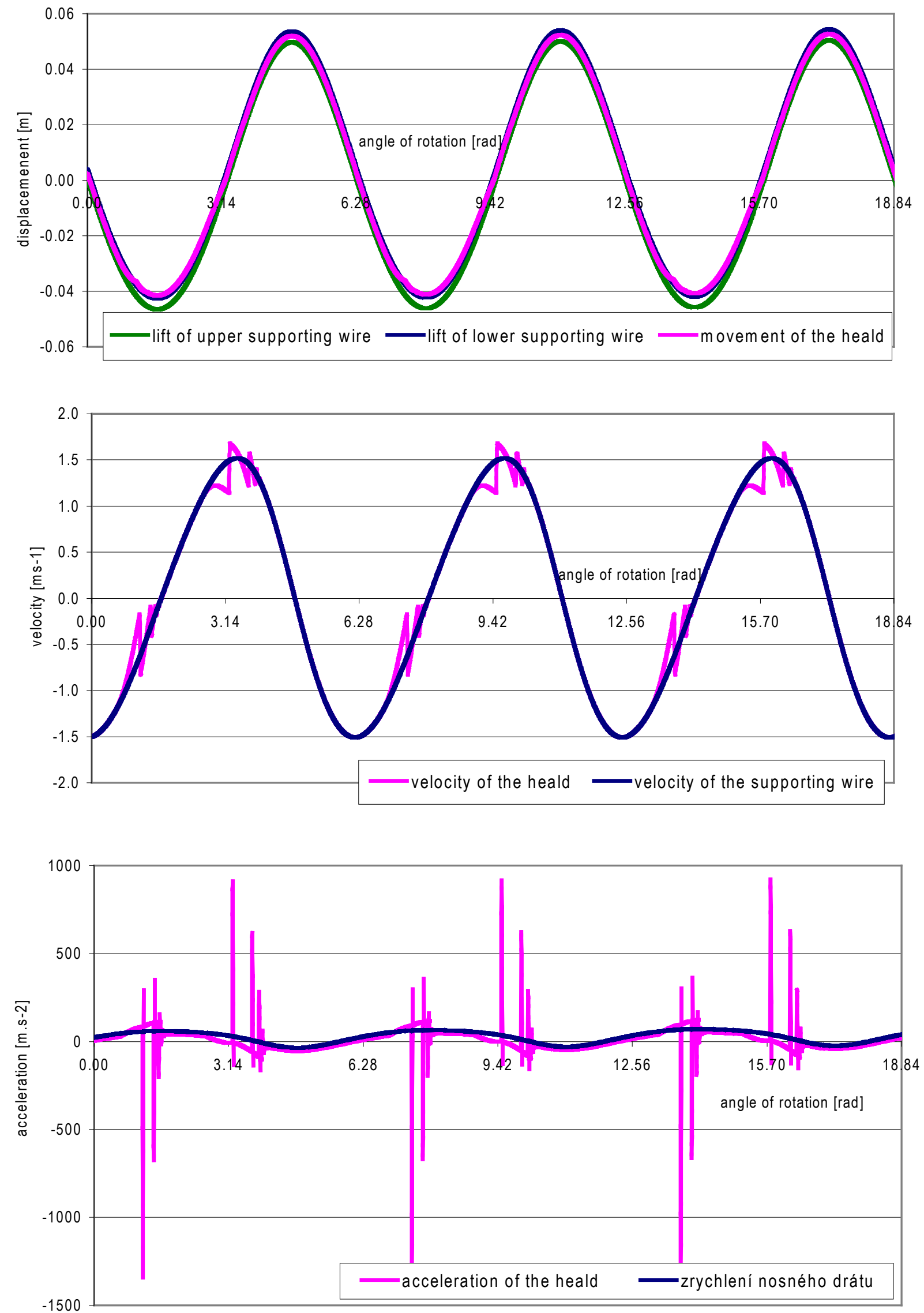

Figure 4. Courses of kinematic quantities of the supporting wire of the heald shaft and of the heald, operating velocity of the shedding motion 300 r. p.m. 
Table 2. Table of the used symbols.

\begin{tabular}{|c|c|c|}
\hline Symbols & Description & Unit \\
\hline$\omega$ & Angular velocity & $\operatorname{rad} . \mathrm{s}^{-1}$ \\
\hline$\Phi$ & Clearance in a joint & $\mathrm{rad}$ \\
\hline$\alpha, \beta, \gamma$ & Angles between the parts of the shedding mechanism & $\mathrm{rad}$ \\
\hline $\mathrm{n}$ & Working speed mechanism & $r-p-m$ \\
\hline $\mathrm{b}_{\mathrm{nH}}$ & Viscous damping coefficient of heald upper part & N.s.m ${ }^{-1}$ \\
\hline$b_{n D}$ & Viscous damping coefficient of heald bottom part & N.s.m ${ }^{-1}$ \\
\hline $\mathrm{b}_{\mathrm{OZ}}$ & Viscous damping coefficient of warp & N.s.m ${ }^{-1}$ \\
\hline $\mathrm{k}_{\mathrm{nH}}$ & Stiffness of heald upper part & $\mathrm{N} \cdot \mathrm{m}^{-1}$ \\
\hline $\mathrm{k}_{\mathrm{nD}}$ & Stiffness of heald bottom part & N. $\mathrm{m}^{-1}$ \\
\hline $\mathrm{k}_{\mathrm{oz}}$ & Stiffness of warp yarn & N. $\mathrm{m}^{-1}$ \\
\hline $\mathrm{T}_{0}$ & Force component acting in the warp direction of healdshaft & $\mathrm{N}$ \\
\hline$\vartheta$ & Height of yarn guides & $\mathrm{m}$ \\
\hline$\phi$ & Clearance in the attachment between supporting wire and heald & $\mathrm{m}$ \\
\hline g & Gravity acceleration & $\mathrm{m} \cdot \mathrm{s}^{-2}$ \\
\hline $\mathrm{y}$ & Height of shed & $\mathrm{m}$ \\
\hline$\lambda$ & Displacement of warp-line & $\mathrm{m}$ \\
\hline $\mathrm{F}_{\mathrm{NL}}$ & Load of healdshaft & $\mathrm{N}$ \\
\hline$m_{n}$ & Weight of heald & $\mathrm{Kg}$ \\
\hline $\mathrm{K}$ & Kinetic energy & $\mathrm{J}$ \\
\hline $\mathrm{U}$ & Potential energy & $\mathrm{J}$ \\
\hline $\mathrm{R}$ & Dissipative function & $\mathrm{J}$ \\
\hline $\mathrm{D}$ & Dissipative energy & $\mathrm{J}$ \\
\hline $\mathrm{U}$ & Dissipative work & $\mathrm{J}$ \\
\hline $\mathrm{k}_{2}, \mathrm{k}_{4}, \mathrm{k}_{61}$ & Torsional stiffness & N.m.rad ${ }^{-1}$ \\
\hline $\mathrm{b}_{2}, \mathrm{~b}_{4}, \mathrm{~b}_{61}$ & Viscous damping torsional coefficient & N.m.s.rad ${ }^{-1}$ \\
\hline$I_{2 P}, I_{4}, I_{41}, I_{6}, I_{6 L}$ & Moment of inertia & $\mathrm{kg} \cdot \mathrm{m}^{2}$ \\
\hline$\varphi_{\mathrm{ip}}, \varphi_{\mathrm{iP}}$ & Rotation of parts of the mechanism & $\mathrm{rad}$ \\
\hline$\phi_{\text {iP }}, \phi_{\text {iP }}$ & Angular velocity of parts of the mechanism & rad. $\mathrm{s}^{-1}$ \\
\hline$\varphi_{i \mathrm{P},} \varphi_{\mathrm{iP}}$ & Angular acceleration of parts of the mechanism & $\operatorname{rad} . \mathrm{s}^{-2}$ \\
\hline$M_{4 L}, M_{6 L}$ & Weight of heald-frame and parts of the mechanism used for its stroke & $\mathrm{kg}$ \\
\hline $\mathrm{F}_{\mathrm{NL}}$ & Load of the heald-frame & $\mathrm{N}$ \\
\hline
\end{tabular}

\section{References}

[1] Mrázek, J.: Theoretical analysis of dynamics four-bar beat up mechanisms of a loom. In.: Mechanism and machine theory, Pergamon Press, 1992, pp. 125-136. USA

[2] Bílek, M.; Mrázek, J. Dynamic Stress of Heald Shaft of Weaving Looms. Vlákna a textil, 1998, no.3, pp. 131-134, Slovakia.

[3] Beran J.; Bílek M. Matematické modelování základních mechanismů tkaciho stroje. In TRANSFER 2000. Trenčín: TnU, Slovensko, 2000. s 25-30.

[4] Recep E.; Gülcan Ö.; Yildiray T.: Kinematics of Rotary Dobby and Analysis of Heald Frame Motion in Weaving Process. Textile Research Journal, 2008 Vol. 78, No. 12, pp. 1070-1079, USA,

[5] Eren R.; Ozkan G; Mehmet Karahan M.: Comparison of Heald Frame Motion Generated by Rotary Dobby and Crank \& Cam Shedding Motions. FIBRES \& TEXTILES in Eastern Europe. Vol. 13, No. 4 2005,
[6] Terentyev, V.I., Smirnov, B.N. Dynamics of a shedding mechanism with flexible links. Izvestiya Vysshikh Uchebnykh Zavedenii, Seriya Teknologiya Tekdtil'noi Promyshlennosti - Issue 2, 2011, Pages 80-83. Russia

[7] Korolev, P.A., Lohmanov, V.N. Kinematics of connections of the shedding mechanism of a circular loom TKP110-U. Izvestiya Vysshikh Uchebnykh Zavedenii, Seriya Teknologiya Tekstil'noi Promyshlennosti - Issue 4, 2011, Pages 116-119. Russia

[8] Kapucu, S., Das, M., T., Kilic, A. Cam Motion tuning of Shedding Mechanism for Vibration Reduction of Heald frame. Gazi University Journal of Science - Volume 23, Issue 2, 2010, Pages 227-232. Turkey

[9] Akamura, T., Kinari, T., Shimokawa, T., Miyashita, D., Mochizuki, Y., Shintaku, S. Jumping behavior of heald in a shedding motion of loom. Journal of Textile Engineering , Volume 52, Issue 2, 2006, Pages 87-92. Japan 
[10] BÍLEK, Martin; KOVÁŘ, Šimon. Record of the movement of heald in the weaving loom. In IX. International Conference on the Theory of Machines and Mechanism in association with the II. CEACM Conference on Computational Mechanics 2004. Liberec: TUL, 2004, pp. 87-92.

[11] Bílek, M., Kovár̆, Š.: Mathematical model of the heald shaft of the weaving loom. Buletinul institutului polytehnic din laşi. Technical University of laşi, 2007 laşi, fasc. 5, volume 1, pp. 375-382. Romania

[12] Hong Jun, C., Li Jun, L. Analysis on Warp's Frictional Movement in the Heald Eye during Weaving Process. Advanced materials Research Volume 175-176, January 2011, Pages 490-495.
[13] TUMAJER, P., URSÍNY, P., BÍLEK, M., MOUČKOVÁ, E.: Use of the vibtex vibration system for testing textiles, AUTEX Research Journal, Vol. 11, No2, June 2011, ISSN 1470-9589,

[14] Tumajer P., Ursiny P., Bílek M., Moučková E.; Research Methods for the Dynamic Properties of Textiles. FIBRES \& TEXTILES in Eastern Europe 2011, Vol. 19, No. 5 (88) pp. 33-39.

[15] TUMAJER, P., URSÍNY, P., BÍLEK, M., MOUCKOVA, E., POKORNA M.: Influence of structure of the yarn on mechanical characteristics of yarns exposed to dynamic stress, Autex Research Journal, Volume 12, Issue 2, June 2012, Pages 44-49 